\title{
TRAJETÓRIAS DE FORMAÇÃO INICIAL E CONTINUADA DE BIBLIOTECÁRIOS PARA CARGOS GERENCIAIS EM BIBLIOTECAS: CONTRIBUIÇÕES E LACUNAS
}

\author{
Miriam Alves ${ }^{1}$ \\ Rosângela Fritsch ${ }^{2}$
}

Resumo: $\mathrm{O}$ artigo analisa a formação profissional para o exercício de funções gerenciais de bibliotecários atuantes nas bibliotecas da Universidade Federal do Rio Grande do Sul. Tem abordagem qualitativa e configura-se como estudo de caso. Como técnica de coleta de dados, utilizou bases de dados da UFRGS, documentos, currículo lattes e entrevistas com as gestoras, submetidas à análise de conteúdo. Percebe-se que há uma valorização da pós-graduação, especialmente do Mestrado para o exercício da chefia. Demonstra de que forma as bibliotecárias construíram suas carreiras, agregando conhecimentos da formação inicial em Biblioteconomia, lacunas, e contribuições das formações continuadas.

Palavras-chave: Bibliotecário-gestor. Competência. Competência gerencial.

\section{TRAJECTORIES OF INITIAL AND CONTINUED FORMATION OF LIBRARIANS FOR MANAGEMENTAL POSITIONS IN LIBRARIES: CONTRIBUTIONS AND GAPS}

\begin{abstract}
This article analyzes the professional training for the management of librarianships in the libraries of the Federal University of Rio Grande do Sul. It has a qualitative approach and is configured as a case study. As data collection technique, UFRGS databases, documents, curriculum lattes and interviews with managers were submitted to content analysis. It is noticed that there is a valorization of the postgraduation, especially of the Masters for the exercise of the head. It demonstrates how librarians have built their careers by adding knowledge of initial training in library science, gaps, and the contributions of continuing education.
\end{abstract}

Keywords: Librarian-manager. Competence. Managerial competence.

\footnotetext{
${ }^{1}$ Mestre em Gestão Educacional pela Universidade do Vale do Rio dos Sinos. Bibliotecária da Universidade Federal do Rio Grande do Sul. Endereço: Av. Bento Gonçalves 9500 prédio 43113. Email: miriam.alves@ufrgs.br

${ }^{2}$ Doutora em Educação, pela Universidade do Vale do Rio dos Sinos. Professora do Programa de Pós-Graduação em Educação e do Mestrado em Gestão Educacional na Universidade do Vale do Rio dos Sinos. Endereço: Av. Dr. Nilo Peçanha, 1600, Campus Porto Alegre. Email: rosangelaf@unisinos.br
} 


\section{INTRODUÇÃO}

O desenvolvimento de competências gerenciais é importante para o exercício da gestão em bibliotecas universitárias enquanto organizações que contribuem para atividades de ensino, pesquisa e extensão, próprias das instituições de ensino superior (IES). São atribuições do trabalho do bibliotecário gerenciar unidades como bibliotecas, centros de documentação, de informação e correlatos (UFRGS, 2016a) e pela natureza e responsabilidade inerentes, a formação em gestão se coloca como prioritária. É necessário agregar um conjunto de conhecimentos, habilidades e atributos, os quais nem sempre os bibliotecários se veem investidos ao término da graduação. Hoje, o bibliotecário não é mais requerido somente como um profissional técnico, capacitado para gerir a informação; precisa estar apto a gerir um setor e funcionários sob sua responsabilidade. Administrar uma instituição educacional, é um desafio sob diferentes pontos de vista. Gerenciar equipes constitui uma expertise que exige preparo técnico, gerencial, domínio de novos conhecimentos e desenvolvimento de habilidades e atitudes. Isso exige do bibliotecário, atualização, aprimoramento e desenvolvimento de competências, desde a formação inicial, nas situações de trabalho e por meio da formação continuada. É necessário que todo gestor de biblioteca ou unidade de informação desenvolva habilidades e competências, pois são fundamentais no desempenho de suas funções como líder perante a sua equipe. (SILVA, J., 2009). Ressalta-se que a competência gerencial está diretamente relacionada à qualidade de serviços e produtos em uma biblioteca e o gestor é mediador entre as necessidades de seus usuários e as melhorias no ambiente informacional, estimulando mudanças e inovações.

O objetivo deste artigo é refletir sobre as contribuições, as influências e as lacunas da formação profissional na prática de gestão dos bibliotecários atuantes no Sistema de Bibliotecas da UFRGS (SBUFRGS) em cargos de chefia.

O texto está estruturado em cinco seções, a partir desta introdução. Na segunda seção, traz a revisão de literatura e bibliográfica, apresentando a temática da competência gerencial na produção de conhecimentos acumulada e de que forma a educação continuada pode contribuir no exercício dos cargos de chefia. A terceira traz a metodologia, descreve o método e 


\title{
dAEPE|
}

procedimentos adotados. A quarta seção apresenta os resultados e, por fim, a quinta aponta as conclusões do estudo.

\section{Revisão de literatura e bibliográfica}

Segundo Dubar (2005), os componentes integrantes da identidade social de um indivíduo são a formação profissional e o acesso ao trabalho. A profissionalidade, para o autor, se baseia na articulação entre a formação inicial e o processo de construção e evolução no trabalho. No processo de profissionalização, os saberes profissionais são definidos e construídos e, cada profissão, exigirá conhecimentos, competências e atitudes específicas. Profissão pode ser definida como:

\begin{abstract}
O reconhecimento social dos saberes sociais que ele adquiriu na esfera da formação, bem como dos serviços ou produtos que ele é capaz de oferecer, reconhecimento esse conferido por meio de sua inserção no mercado de trabalho, em posição correspondente ao conhecimento adquirido. Da forma como é aqui entendida, profissão envolve: a) correspondência entre a posição ocupada no mercado de trabalho e os conhecimentos adquiridos na esfera da formação (que pode se realizar no próprio trabalho) b) reconhecimento da validade desses dois elementos - conhecimento e valor social dos serviços - por parte da sociedade, através da inserção desse indivíduo, no mercado de trabalho. (FRANZOI, 2006, p. 50).
\end{abstract}

A trajetória profissional pode ser compreendida como o percurso seguido pelo profissional ao longo da sua vida funcional, ou o conjunto de experiências adquiridas. Dubar (2005) estabelece que a trajetória sócio-profissional tem a profissão, o trabalho e a formação como suas dimensões. A formação é a forma como os profissionais aprendem as funções, que fazem ou irão fazer, pode ou não ser desenvolvida no mesmo ambiente e no mesmo tipo de função. Ortega Y Gasset (1970) veem a trajetória como um processo que abrange os âmbitos individual, grupal e geracional, tecendo assim, modos de ser profissional nas diversas profissões durante as gerações. As trajetórias vão oportunizando experiências ao longo da vida que se agregam ao campo profissional, se inter-relacionando e favorecendo o desenvolvimento de competências.

Há muitas definições para o termo competência, mas costuma-se geralmente utilizá-lo para designar as competências profissionais. Dutra (2004) apresenta três grandes facetas teóricas, sendo que a primeira apresenta competência como um conjunto de qualificações ou 
características implícitas ao indivíduo e que são necessárias para que ele tenha destaque em determinado trabalho ou situação. É a corrente representada por Boyatzis (1982) e MCCLelland (1973). A segunda abordagem, de teóricos franceses como Le Boterf (1999) e Zarifian (1999), destaca a importância do que a pessoa produz ou faz no trabalho. A terceira corrente, de visão integradora reúne as duas anteriores como o conjunto de conhecimentos, habilidades e atitudes, cujo trinômio é conhecido como CHA, os atributos necessários à execução de uma atividade, assim como os comportamentos observáveis no trabalho. (BRANDÃO; BORGES-ANDRADE, 2007).

Valentim corrobora ao afirmar que competência é:

[...] o conjunto de habilidades, destrezas e conhecimentos que um profissional de qualquer área do conhecimento humano precisa contar, para cumprir as atividades especializadas, oferecendo o mínimo de garantia sobre os resultados de seu trabalho, tanto em relação ao seu público, quanto em relação ao seu empregador, em última instância, a sociedade da qual faz parte. (VALENTIM, 2002, p.123)

Existem competências típicas para o cargo de gestor. Ruas (2000, p. 6) conceitua a competência gerencial como "[...] a capacidade de mobilizar, integrar e colocar em ação conhecimentos, habilidades e formas de atuar a fim de atingir/superar desempenhos configurados na missão da empresa e da área".

Nem todos os indivíduos têm as competências necessárias para o desempenho de determinadas atividades na área de gestão. Para o desenvolvimento de competências existem formas de aprendizagem formal e informal, a primeira associada em geral, a ações de treinamento e educação e a segunda por formas de aprendizagem diversas, como, por exemplo, capacitações, eventos e leituras, muitas vezes por iniciativas dos próprios profissionais. (PANTOJA; BORGES-ANDRADE, 2009).

Motta (2004) utiliza a palavra gestor para tratar da coexistência de aspectos de liderança e gerenciais numa perspectiva dialógica da ação, o que exige uma flutuação da importância destas atribuições definidas pelas circunstâncias. Reitera que o aprendizado sobre gerência não se dá somente formalmente, mas em interação com a realidade em que vive, e dela extraindo experiência. 
Para Le Bortef (2003) cabe ao indivíduo a responsabilidade pelo constante exercício do aprender a aprender, em um processo contínuo de aprendizagens formais e/ou informais, cujos resultados são novas experiências e vivências, sempre transformadoras e passíveis de aprimoramento. A esta atualização ou aperfeiçoamento costuma-se chamar comumente de educação continuada ou formação continuada, que é definida por Cunha (1984, p.150) como: “[...] qualquer aprendizagem, formal ou informal, feita a partir da primeira graduação".

A revisão de literatura ${ }^{3}$ selecionou seis trabalhos que se aproximam da categoria "Formação Continuada" e trazem uma reflexão quanto à importância da continuação dos estudos para melhores colocações no trabalho, e também evidências de que a graduação não está preparando o profissional para o mercado atual (ALMEIDA; BAPTISTA, 2011; CONCEIÇAO, 2011; MATTOS, 2012; MONTAGNER, 2013; SILVA; Cláudia; PONTES, 2013; SILVA, Carla, 2011).

A importância da formação continuada como forma de agregar conhecimentos está presente no trabalho de Silva e Pontes (2013), cujo estudo contribui para o fortalecimento e ampliação dos cursos de pós-graduação strictu e latu sensu como condição indispensável para a qualificação da Biblioteconomia e preparação dos profissionais para significativas mudanças no contexto do trabalho. Almeida e Baptista (2011) destacam a importância dos bibliotecários adquirirem competências para desempenharem melhor suas funções e não tornarem a profissão obsoleta. De modo geral, as pesquisas sobre formação continuada apontam a importância do investimento futuro na profissão, como forma dos profissionais desempenharem competentemente suas funções, se mantendo atualizados.

Na categoria "Desenvolvimento Profissional” selecionou-se nove títulos, que tratam sobre os processos formativos nas trajetórias profissionais, competências profissionais, constituição de saberes, construção de carreiras e formação profissional, aproximando-se do tema formação continuada (GOMES, 2012; LINZMEYER, 2014; MATIAS, 2012; RESCHKE, 2014; ROSSI, 2012; SEPÚlVEDA, 2012; SILVA, R., 2012; VIANA, 2012; WIGGERS, 2015;). Foi possível

3 Utilizou-se o Portal de Periódicos da Capes, para rastreamento e seleção de artigos e a Biblioteca Digital de Teses e Dissertações do Instituto Brasileiro de Informação em Ciência e Tecnologia para teses e dissertações; como filtros o período de 2010 a 2015e língua portuguesa idioma; como descritores: Bibliotecário, Bibliotecários, Competências, Competências Gerenciais, Gestão, Biblioteca universitária, Bibliotecas universitárias, Gestor, Gestores, Trajetórias profissionais e Trajetória profissional e o operador booleano AND para fazer as combinações possíveis entre os termos. 
refletir sobre a responsabilidade pessoal no desenvolvimento da carreira e em como o bibliotecário que almeja tornar-se gestor necessita buscar áreas que venham ao encontro das funções atribuídas ao cargo. Rossi (2012) destaca que embora haja um gap de competências nos profissionais da informação, é importante que os mesmos busquem suprir esta lacuna para melhorar seu desenvolvimento pessoal e profissional. Linzmeyer (2014) conclui que o desenvolvimento da carreira na contemporaneidade de trabalhadores das mais diversas áreas é um processo consciente e responsável do trabalhador. É possível traçar um paralelo ao afirmar que o bibliotecário gestor necessita buscar o desenvolvimento de atributos e aptidões que o qualifiquem para tal.

Investir na carreira por meio da formação continuada é uma alternativa para trazer maior familiaridade com a função e mesmo sendo tarefa do indivíduo se manter atualizado, é importante que a instituição onde ele atue, também promova e incentive seu crescimento.

\section{METODOLOGIA}

A pesquisa teve abordagem qualitativa, e em relação ao método adotado, configura-se como estudo de caso único, que segundo Yin (2010, p.39) “[...] é uma investigação empírica que investiga um fenômeno contemporâneo dentro de seu contexto da vida real, especialmente quando os limites entre o fenômeno e o contexto não estão claramente evidentes".

A produção de dados se deu em bases da Pró-reitoria de Gestão de Pessoas (Progesp), currículo Lattes e, especialmente, entrevistas semiestruturadas com 10 (dez) bibliotecárioschefe que serão nomeadas com E1, E2, E3, sucessivamente (BONI E QUARESMA, 2005).

Os critérios para escolha dos entrevistados foram: diversidade da educação formal e tempo de experiência na função de gestor superior a cinco anos. As entrevistas foram submetidas ao método da análise de conteúdo de Bardin (2010).

Como categorias na temática Trajetórias profissionais e Formação emergiram Graduação e Formação Continuada e as subcategorias: influências, contribuições, lacunas e na formação continuada ainda expectativas em relação aos estudos.

\section{RESULTADOS}


O SBUFRGS é composto por 206 técnicos, sendo 126 bibliotecários, 33 deles em cargos de chefia distribuídos em 31 bibliotecas setoriais universitárias distribuídas entre os seis campi da UFRGS e 1 biblioteca escolar coordenadas pela Biblioteca Central.

De acordo com a Classificação Brasileira de Ocupações (CBO) são requisitos de qualificação para ingresso no cargo, o curso superior em Biblioteconomia e a habilitação profissional por meio de registro no Conselho competente, segundo a lei n. 9.674 de 26 de julho de 1998. (UFRGS, 2016b). O nível de classificação para ingresso no cargo de Bibliotecário/Documentalista é o E.

As principais atribuições do cargo são, além das atividades técnicas, o gerenciamento de unidades como bibliotecas, centros de informação, redes e sistemas de informação, executando planos e atividades, além da elaboração de políticas de funcionamento. (UFRGS, 2016b) ficando explícita a importância da atividade como gestor.

A Escola de Desenvolvimento de Servidores da Universidade Federal do Rio Grande do Sul (EDUFRGS) promove a capacitação de servidores, com a oferta e a orientação de várias atividades de aprendizagem interdependentes, que visam o desenvolvimento pessoal e profissional do servidor. O servidor escolhe conforme seu interesse e disponibilidade, em atendimento às necessidades do trabalho e aos objetivos da instituição, sendo facultado ao servidor a progressão dentro da carreira. (UFRGS, 2016c). A Universidade também incentiva os servidores a ampliarem sua qualificação realizando cursos de educação formal concedendo incentivos educacionais, por meio de editais. De acordo com o nível de escolaridade e relação direta à sua área de atuação, existe uma tabela com percentuais que incentivam o servidor à continuação dos estudos. (UFRGS, 2016d). É oferecida, também, a isenção do pagamento de mensalidades em cursos de pós-graduação (lato sensu) como forma de estímulo. (UFRGS, 2016e). Percebe-se que há incentivo para que os servidores se qualifiquem, no entanto, após chegar ao topo do Plano de Carreira não há mais progressão podendo gerar desmotivação nos servidores.

a) Registra-se que a globalização ocasionou muitas modificações no mundo do trabalho, como o aumento da competição, o que acabou estendendo-se também às bibliotecas. Para Nascimento, Couto e Bastos (2000), os gerentes de bibliotecas precisam hoje atuar em ambientes organizacionais dinâmicos e complexos em que há variabilidade e temporalidade de 


\title{
REVISTA DE ADMINISTRAÇÃO EDUCACIONAL
}

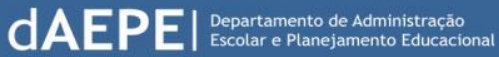

valores, objetivos e métodos. Os autores discutem a valorização dos cursos de Biblioteconomia na formação deste novo profissional com capacidade para assumir funções administrativas e de planejamento, conduzir equipes, etc.

b) Foi questionado às bibliotecárias-chefe, quanto à influência que o curso de Biblioteconomia teve no seu cargo de gestora. Além dos exemplos das professoras, foi destacada a importância dos estágios na obtenção da experiência aliada à teoria:

"[...] eu me sinto assim: eu terminei meu curso e eu me entendi preparada para atuar na biblioteca. É, por quê? Porque eu fiz estágios, né? Não fiquei só no curso. Trabalhava já aqui, me senti preparada”. (E 3).

Nas contribuições do curso para atuação como gestoras, destacam a organização da informação tecnicamente, em detrimento da parte administrativa:

“Da parte técnica, perfeita [...]”. (E 1).

"Se for no lado da gestão, foram muito poucas [...]". (E 2).

Como lacunas, enfatizam a necessidade de o curso ter um olhar mais voltado à gestão e menos à técnica. Destacam ainda que a experiência como gestoras se deu muito mais pela própria vivência na função:

\footnotetext{
"Realmente, elas tiveram origem mais da minha experiência profissional do que por conta da graduação". (E 2).
}

\begin{abstract}
"Bom, como eu to te dizendo, a vida inteira eu tive numa função dessa natureza. Às vezes em hierarquias diferentes, mas a função sempre a mesma [...] Então, eu acho que a trajetória como um todo trouxe facilidades para o meu cargo atual" (E 7).
\end{abstract}

Motta, (2004, p.27) ressalta que a "capacidade gerencial é mais rara, exige habilidades mais complexas: capacidade analítica, de julgamento, de decisão e de enfrentar riscos e incertezas". Para ele, a formação do gestor se dá no meio de suas práticas gerenciais, sejam boas ou más e desta forma, fortalecendo a sua capacidade de análise na resolução de problemas, tomando consciência de alternativas comportamentais e conhecendo seu melhor estilo gerencial.

E8 reforça que a experiência é mais importante que a teoria: 


\section{REVISTA DE ADMINISTRAÇÃO EDUCACIONAL}

"Acredito haver cursos que deem as bases teóricas da gestão, mas não cursos que 'ensinem a ser' gestor; $90 \%$ da base da gestão está centrada na experiência como gestor”. (E 8).

As experiências de vida ou profissionais e o conhecimento das rotinas de trabalho agregam maior familiaridade com as rotinas de gestão.

"Experiências várias, não só profissionais. Ser gestor, na função de chefe de uma biblioteca significa tratar com pessoas. Diria eu, são importantes para tal, tanto as experiências de vida, com aquelas de relações de trabalho. No âmbito exclusivamente profissional, as experiências decorrem do dia-a-dia do trabalho, expressos na familiaridade com as rotinas da biblioteca, com o fluxo do trabalho e, por tratar-se de biblioteca especializada que atua com um público específico, conhecer as pessoas que buscam nossos serviços, seus interesses e área dos assuntos do acervo". (E 8).

\section{A influência dos relacionamentos existentes tanto com os superiores como com outros}

funcionários foi destacada como fator importante para o exercício da gestão:

“[...] ter uma boa relação em geral com os docentes, com os professores, ter uma boa relação geral com todos, mas principalmente com essas pessoas que tenham assim uma conotação política, no caso né? Que às vezes precisa, a gente precisa deles pra fazer alguma coisa na biblioteca, não tem recursos próprios, então tu tem que ter essa... boa vontade vamos dizer assim... esse relacionamento bom os gestores acima de ti, como o diretor da unidade, os professores, né? Os próprios administrativos, outros funcionários, né? (E 1).

O fato de trabalhar sozinha pode também contribuir no desenvolvimento como gestora:

"[...] eu trabalhei em outras, em outros lugares que eu era a única bibliotecária, [...] e de outros tipos de trabalhos assim com quem tu não tem com quem dividir né, as tarefas de gestão e do próprio trabalho de bibliotecário, né? Acho que isso foi um fator de crescimento, assim" (E 5).

As bibliotecárias destacam que a chefia de bibliotecas não é almejada na Universidade.

"Eu nunca quis chefia, não queria chefia, nunca quis [risos]. Mas, aconteceu né? É assim que acontecem as coisas, na UFRGS principalmente, né? Tem que assumir, não tem outro jeito". (E 10). 
De fato, a função gratificada desencoraja os profissionais que precisam assumir tantas responsabilidades, além de se sentirem desprestigiados e desvalorizados em sua função, sem reconhecimento social.

Percebe-se que adquiriram as experiências profissionais cada uma a seu modo. Construíram seus conhecimentos pelo conjunto de experiências pessoais e profissionais, desenvolvendo aptidões e desenvolvendo novas competências (DUBAR, 2005). Não há uma fórmula pronta de como ser gestor, mas é necessário abertura para as experiências que surgem no dia-a-dia. É o que assegura Motta (2004), quando diz que o aprendizado da gerência se dá da própria capacidade de solucionar problemas.

E3 destaca uma crise de identidade e despreparo do aluno de Biblioteconomia

"Acho que sim, acho que deixa lacunas sim [...] mas o que eu penso assim, é... com relação ao currículo né? Que a nossa profissão, tá faltando, saber o porquê. O que é isso, o quê que eu faço, em que eu vou trabalhar, afinal de contas? [...]. A lacuna talvez que eu veja é no sentido do que seria nosso diferencial enquanto profissionais, né? A gente vai trabalhar com o que daqui a 20 anos? Né? Com informação. Sim, mas como é que a gente vai tratar essa informação, né’? (E 3).

As bibliotecárias destacaram lacunas relativas à formação tradicional versus formação tecnológica, que ficaram evidentes nas falas a seguir.

\begin{abstract}
"Bem, claro que quando eu fiz a faculdade, nem se falava em banco de dados, não se falava em nada disso, então realmente ele deixou toda esta lacuna que eu acabei preenchendo depois". (E 4).
\end{abstract}

A entrevistada 8, considera que a automação não deva ser supervalorizada visto que o profissional, em um país como o Brasil, com diversidade de recursos, pode ser designado para bibliotecas sem as mínimas condições materiais. Precisa ser capaz de desempenhar seu papel de mediador da informação não podendo contar somente com a tecnologia:

"É correto dizer que a automação avança vertiginosamente e que este conhecimento é indispensável aos futuros profissionais, mas também seria necessário atentar para a formação de profissionais aptos a atuarem em quaisquer condições". [grifo da entrevistada]. (E 8).

Para os bibliotecários, que ainda costumam ser vistos como profissionais tecnicistas, a formação continuada possibilita a capacitação no manejo de novas tecnologias e em atividades 


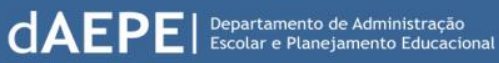

tipicamente gerenciais, proporcionando uma aproximação com estas responsabilidades do cargo.

Muitos profissionais chegam a chefias de bibliotecas, despreparados e com poucos fundamentos da área administrativa, e é importante algum tipo de formação continuada que lhes traga uma aproximação com a função. Para Prosdócimo e Ohira (2000), os bibliotecários necessitam transcender sua formação específica, o que vai além de elevar seu nível de educação, mas desenvolver maior capacidade de interação com as equipes de trabalho, a fim de enfrentar as crescentes mudanças.

As bibliotecárias quando questionadas sobre quais as contribuições percebidas da formação continuada sobre seu exercício enquanto gestoras apontaram que em sua maioria realizaram cursos oferecidos pela Universidade, desde os mais simples, como os de informática até os da área de gestão que lhes possibilitaram maior conhecimento das atividades de planejamento e organização de suas bibliotecas.

"É, eu acho que esses cursos que eu fiz lá no começo, eles foram bons por isso, porque são cursos que realmente eu acho que no início da carreira fazem mais diferença né? Pra tu conseguir organizar até teu próprio trabalho porque quando a gente começa, quer fazer tudo, e não dá conta de nada, né? Principalmente quando a gente é sozinho então a gestão do tempo, sabe, isso aí é importante [...] pra tu conseguir organizar as atividades, até pra passar atividades, pra tu descentralizar as coisas, pra tu delegar coisas, então, assim, pra esse tipo de coisa, esse tipo de treinamento, acho extremamente importante". (E 4).

Destacaram como contribuição da formação continuada a troca de experiências entre gestores em cursos, comissões, eventos e grupos de estudo. As profissionais não hesitaram em aproveitar as oportunidades, seja em grupos de estudos que se formam por pares de interesse, ou por meio dos cursos oferecidos na Universidade, como forma a se manterem atualizadas, se aperfeiçoarem e melhorarem as atividades da profissão.

Das gestoras entrevistadas, apenas 1 (uma) permaneceu na primeira formação, tendo realizado diversos cursos de capacitação oferecidos pela Universidade. A Especialização é a escolaridade dominante, no entanto dos 24 bibliotecários mestres na Universidade, 7 (sete) são bibliotecários-chefe, o que leva a crer que há interesse dos profissionais em continuar os estudos em nível de Mestrado, ou já chegam na Universidade com maior formação, sendo um incentivo a exercerem a chefia. As bibliotecárias-chefe especialistas encontram-se na faixa etária dos 50 


\title{
REVISTA DE ADMINISTRAÇÃO EDUCACIONAL
}

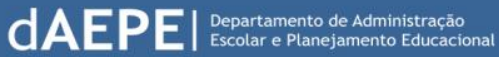

aos 59 anos, enquanto que o contingente dos mestres é mais jovem, encontra-se na faixa dos 30 aos 39 anos.

A formação continuada permite aos bibliotecários auxiliar e entender as próprias práticas profissionais, conhecer a comunidade usuária a qual atendem, trocar conhecimentos com colegas de profissão por meio dos eventos científicos e ainda facilitar a ascensão profissional nos locais de atuação. Sobre as expectativas em relação à continuação dos estudos as respostas se dividiram entre aquelas que têm certeza de quererem continuar, as que têm dúvidas e as que não querem. Dentre as que têm certeza, a maioria quer manter-se atualizada ou gosta da pesquisa.

\begin{abstract}
"Porque eu acho muito importante a gente se manter atualizado nas coisas que estão acontecendo e eu acho que, na altura que eu me encontro na minha trajetória profissional, se eu ficar estagnada, é melhor que eu saia do mercado e deixe espaço pra outro né? Então ou eu fico buscando me manter em dia ou dá espaço. Como eu não to querendo sair, eu procuro me manter em dia. [risos]". (E 7).
\end{abstract}

As dúvidas são geralmente relacionadas à busca por cursos na sua área de atuação, para se sentirem mais confortáveis, o que nem sempre é possível ou por quererem algo inovador como nos diz a entrevistada 9:

\begin{abstract}
"No meu caso, seria o Doutorado. Ah, já pensei várias vezes, né, mas assim, como o Doutorado é muito vinculado assim, à docência e, assim, isso eu já tenho, apesar de ser uma coisa que eu gosto de fazer, dar treinamento, mas quando eu vejo assim, bah, 4 anos, né então assim, eu fico... já tive várias idas e vindas. Esse ano eu vou e aí sempre recuo, né? Então eu não tenho uma resposta assim, dizer 'não vou fazer', mas assim, no momento isso tá em standby assim, bem, bem [grifo da entrevistada], lá embaixo, assim". (E 9).
\end{abstract}

Dentre as que não pretendem continuar a estudar estão os casos de aposentadoria iminente ou timidez. Assim, vê-se que a maioria das bibliotecárias gestoras que ainda estão ativas na Universidade pretende continuar os estudos como forma de atualização ou pelo gosto de estudar. 


\section{CONCLUSÕES}

As influências do curso de Biblioteconomia para o cargo de gestor foram creditadas mais ao exemplo de professoras e ao trabalho nos estágios. As contribuições destacadas foram a organização e gestão do conhecimento, consideradas como base para a profissão. As lacunas apontadas foram a gestão de pessoas, déficit de identidade e despreparo dos alunos com o curso e formação tradicional versus tecnológica.

Em geral, há interesse em continuarem seus estudos, seja para se atualizarem e aperfeiçoarem, seja pelo gosto à pesquisa. A Especialização é a escolaridade dominante, e entre os mais jovens que possuem Mestrado, este aparece como fator motivador para exercer a chefia. As influências percebidas se deram pelos estágios e exemplo de professoras, que aliaram a prática à teoria. A principal contribuição da graduação foi a organização técnica da informação e a lacuna foi a gestão.

As bibliotecárias foram buscar formações para suprir lacunas da graduação que se deram por cursos de qualificação e de capacitação oferecidos pela Universidade. Quanto à formação inicial, as revisões dos currículos de Biblioteconomia se evidenciam como prioridade, de forma a atender a necessidade de disciplinas voltadas à gestão, em especial à gestão de pessoas.

Podem ser oferecidos mais cursos de extensão e pós-graduação lato sensu voltados à área biblioteconômica, como o de Especialização em Gestão de Bibliotecas Universitárias. Sugere-se a criação dos cursos de Mestrado e Doutorado em Biblioteconomia e Ciência da Informação que ainda não são disponibilizados no RS. Também que bibliotecários sejam estimulados a participar de Programas de Desenvolvimento de Gestores como pré-requisito para assumirem cargos de gestão em bibliotecas. Considera-se relevante perceberem as exigências da sociedade em constante mutação e que busca profissionais que não sejam somente qualificados para o trabalho, mas capazes de refletirem sobre si mesmos, sua atuação na sociedade e sobre sua própria prática profissional.

\section{REFERÊNCIAS}




\section{REVISTA DE ADMINISTRAÇÃO EDUCACIONAL}

ALMEIDA, Neilia Barros Ferreira de.; BAPTISTA, Sofia Galvão. Profissional da informação: imagem, perfil e a necessidade da educação continuada. Revista Ibero-Americana de Ciência da Informação, [S.1.], v. 2, n. 2, p. 1-14, abr. 2011.

BARDIN, Laurence. Análise de conteúdo. 4.ed. Lisboa: Edições 70, 2010.

BONI, Valdete; QUARESMA, Sílvia Jurema. Aprendendo a entrevistar: como fazer entrevistas nas Ciências Sociais. Revista Eletrônica dos Pós-Graduandos em Sociologia Política da UFSC. Florianópolis, v.2, n.1, jan/jul. 2005.

BOYATZIS, Richard. E. The competent management: a model for effective performance. New York: John Wiley, 1982.

BRANDÃO, Hugo Pena; BORGES-ANDRADE, Jairo Eduardo. Causas e efeitos da expressão de competências no trabalho: Para entender melhor a noção de competência. Revista de Administração Mackenzie, São Paulo, v. 8, n 3, p. 32-49, 2007.

CONCEIÇÃO, Wilma Gravatá da. Competência em informação na perspectiva da educação continuada: um olhar sob a práxis do profissional da informação; Dissertação (Mestrado em Ciência da Informação). Programa de Pós-Graduação em Ciência da Informação da Universidade Federal da Bahia, 2011.

CUNHA, Murilo Bastos da. O desenvolvimento profissional e a educação continuada. Revista de Biblioteconomia de Brasília. Brasília, v.12, n.2, p. 149-156, jul./dez. 1984.

DUBAR, Claude. A socialização: construção das identidades sociais e profissionais. São Paulo: Martins Fontes, 2005.

DUTRA, J. S. Competências: conceitos e instrumentos para a gestão de pessoas na empresa moderna. São Paulo: Atlas, 2004.

FRANZOI, Naira Lisboa. Entre a formação e o trabalho: trajetórias e identidades profissionais. Porto Alegre: Ed: da UFRGS, 2006.

GOMES, Marta Quintanilha. Trilhas profissionais na educação infantil: os sentidos atribuídos ao lugar de atuação pelas professoras da rede municipal de ensino de Porto Alegre. Tese (Doutorado em Educação). Faculdade de Educação. Programa de Pós-Graduação em Educação. Universidade Federal do Rio Grande do Sul. 2012.

LE BOTERF, Guy. Competénce et navigation professionnelle. Paris: Editions d'Organisation, 1999. 
LE BOTERF, Guy. Desenvolvendo a competência dos profissionais. 3. ed. Porto Alegre: Artmed, 2003.

LINZMEYER, Simone Maria Virmond Vieira. Carreiras contemporâneas: responsabilidade pessoal e desafios na trajetória profissional. Tese (Doutorado em Psicologia Social). Programa de Pós-Graduação em Psicologia. Instituto de Psicologia da Universidade de São Paulo. 2014.

MATIAS. Bárbara Ferreira. Narrativas de professoras: análise da construção dos saberes da prática de profissionais com experiência reconhecida. Dissertação (Mestrado em Educação). Programa de Pós-Graduação em Educação. Universidade Federal de Viçosa, MG. 2012.

MATTOS, Valéria Bettio de Trajetórias profissionais de mestres e doutores egressos da Universidade Federal de Santa Catarina: inserção no mundo do trabalho. Tese (Doutorado em Educação). Universidade Federal de Santa Catarina, Centro de Ciências da Educação. Programa de Pós-Graduação em Educação, 2012.

MCCLELLAND, D. Testing for competence rather than intelligence. American Psychologist, v. 28, n. 1, p. 1-14, 1973.

MONTAGNER, Silvia Regina. Caminhos da docência que se entrecruzam e se revelam no processo de formação continuada com os docentes do PROEJA FIC. Dissertação (Mestrado em Educação). Programa de Pós-Graduação em Educação da Universidade Federal de Santa Maria, RS, 2013.

MOTTA, Paulo Roberto. Gestão contemporânea: a ciência e a arte de ser dirigente. 15.ed. Rio de Janeiro; São Paulo: Record: 2004.

NASCIMENTO, C.M.P.; COUTO, A.M.S.; BASTOS, Maria Maia S. A biblioteca universitária hoje: gerência compartilhada. In: SEMINÁRIO NACIONAL DE BIBLIOTECAS UNIVERSITÁRIAS, 11., 2000, Florianópolis. Anais...Florianópolis: UFSC, 2000. Disponível em: <http:/ www.ndc.uff.br/textos/t026.pdf>. Acesso em 28 dez. 2016.

ORTEGA Y GASSET, José. Obras Completas. Revista Del Occidente, Madrid, v.5, 1970.

PANTOJA, Maria Júlia; BORGES-ANDRADE, Jairo Eduardo. Estratégias d e aprendizagem no trabalho em diferentes ocupações profissionais. RAC-Eletrônica, v. 3, n. 1, p. 41-62, 2009.

PROSDÓCIMO, Zulma Pures Alves; OHIRA, Maria Lourdes Blatt. Quem é o bibliotecário em exercício no Estado de Santa Catarina: necessidade de educação continuada. In: CONGRESSO 
BRASILEIRO DE BIBLIOTECONOMIA E DOCUMENTAÇÃO. Anais ... 19. 2000, Porto Alegre. 1 CD-ROM.

RESCHKE, Maria Janine Dalpiaz. Coerência e contradição: o conteúdo e a forma no exercício da docência de didática nos cursos de licenciatura. Tese (Doutorado em Educação). Programa de Pós-Graduação em Educação da Universidade do Vale do Rio dos Sinos. 2014.

ROSSI, Tatiana.Gestão de competências na prestação de serviços de informação em bibliotecas de universidades da região de Florianópolis/SC. Dissertação (Mestrado em Ciência da Informação). Programa de Pós-Graduação em Ciência da Informação do Centro de Ciências da Educação. Universidade Federal de Santa Catarina. 2012.

RUAS, Roberto Lima. A problemática do desenvolvimento de competências e a contribuição da aprendizagem organizacional. In: FLEURY, Maria Tereza Leme; OLIVEIRA JR. Moacir de Miranda. (Orgs.). Gestão estratégica do conhecimento: integrando aprendizagem, conhecimento e competências. São Paulo: Atlas, 2000.

SEPÚLVEDA, Maria Inês Moreira. A relação dos bibliotecários com a profissão, com a rotina profissional e com os usuários a partir de uma perspectiva compreensiva. Dissertação (Mestrado em Ciência da Informação). Programa de Pós-Graduação da Escola de Ciência da Informação. Universidade Federal de Minas Gerais. 2012.

SILVA, Carla Odete Balestro. Ad-mirando o professor de formação técnica: o fazer-se docente no encontro com o PROEJA em dois campi IFSUL. Dissertação. (Mestrado em Educação). Faculdade de Educação. Programa de Pós-Graduação em Educação. Universidade Federal do Rio Grande do Sul. 2011.

SILVA, Claudia Lourenço da; PONTES, Vanildo Pereira. A pós-graduação no processo formacional do bibliotecário: concepções e reflexões teóricas. Biblios. Revista electrónica de bibliotecología, archivología y museología, n.53, p. 29-39, 2013.

SILVA, Janaina da Costa. O estilo de liderança dos bibliotecários de Brasília. 2009. $166 f$. Dissertação (Mestrado em Ciência da Informação) - Faculdade de Economia, Administração, Contabilidade e Ciência da Informação, Universidade de Brasília. 2009.

SILVA, Rosangela Vianna Alves da Trajetórias profissionais de executivas aos postos de alto escalão: fatores-chave, barreiras, inibidores de ascensão e estratégias de enfrentamento. Tese (Doutorado em Administração). Escola Brasileira de Administração Pública e de Empresas. 2012.

UNIVERSIDADE FEDERAL DO RIO GRANDE DO SUL. Biblioteconomia. Disponível em: 


\section{REVISTA DE ADMINISTRAÇÃO EDUCACIONAL}

$<$ http://www.ufrgs.br/ufrgs/ensino/graduacao/cursos/exibeCurso?cod_curso=304> Acesso em 12 jul. 2016 a.

UNIVERSIDADE FEDERAL DO RIO GRANDE DO SUL. Escola de Desenvolvimento da Universidade Federal do Rio Grande do Sul. Desenvolvimento na Carreira. Progressão por Capacitação. Técnico Administrativo. Disponível em: <http://www.ufrgs.br/edufrgs/daoc/tecnico-administrativo/progressao-por-capacitacaoprofissional>. Acesso em: 01. dez. 2016d.

UNIVERSIDADE FEDERAL DO RIO GRANDE DO SUL. Pró-reitora de Gestão de Pessoas. Plano de carreira dos cargos técnico-administrativos em educação descrição do cargo. Disponível em: < http://www.ufrgs.br/progesp/progesp-1/setores/ccma/dima/descricao-doscargos/cargos-de-nivel-e\#7>. Acesso em 11 jul. 2016b.

UNIVERSIDADE FEDERAL DO RIO GRANDE DO SUL. Escola de Desenvolvimento da Universidade Federal do Rio Grande do Sul. Qualificação. Isenção de pagamento de taxa em curso de Especialização. Disponível em: <http://www.ufrgs.br/edufrgs/qualificacao/isencao-de-

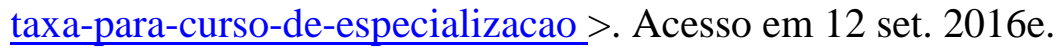

UNIVERSIDADE FEDERAL DO RIO GRANDE DO SUL. Escola de Desenvolvimento da Universidade Federal do Rio Grande do Sul.Trilhas de Aprendizagem. Disponível em: http://www.ufrgs.br/edufrgs/dqa/acoes-de-aperfeicoamento/trilhas-de-apredizagem. Acesso em 12 set. $2016 \mathrm{c}$.

VALENTIM, Marta Lígia Pomin. Formação: competências e habilidades do profissional da informação. In: VALENTIM, Marta Lígia Pomin (Coord.). Formação do profissional da informação. São Paulo: Polis 2002.

VIANA, Stella Pimenta. As significações e repercussões do percurso formativo de pedagogo(as) egressos(as) do projeto Paranoá em suas trajetórias profissionais na educação de jovens e adultos. Dissertação (Mestrado em Educação). Faculdade de Educação. Universidade de Brasília. 2012.

WIGGERS, Letícia Helena Frozin Fernandes Cruz. Memórias e experiências do fazer-se professor na educação profissional: Escola Técnica Federal de Santa Catarina -ETFSC (19682010). Dissertação (Mestrado em Educação). Programa de Pós-Graduação em Educação. Universidade Federal de Santa Catarina. 2015.

YIN, Robert K. Estudo de Caso: Planejamento e Métodos. 3. ed. Porto Alegre: Bookman, 2010.

ZARIFIAN, P. Objectif compétence: pour une nouvelle logique. Paris: Editions Liaisons, 1999. 